\title{
Chemical composition of horse-chestnut (Aesculus) leaves and their susceptibility to chestnut leaf miner Cameraria ohridella Deschka \& Dimić
}

\author{
Maja Paterska $^{1}$ Hanna Bandurska ${ }^{1} \cdot$ Joanna Wysłouch $^{1} \cdot$ Marta Molińska-Glura $^{2}$. \\ Krzysztof Moliński ${ }^{3}$
}

Received: 14 June 2016/Revised: 7 December 2016/Accepted: 18 March 2017/Published online: 25 March 2017

(C) The Author(s) 2017. This article is an open access publication

\begin{abstract}
For over 20 years, trees of Aesculus spp. have been attacked by the larvae of Cameraria ohridella, which causes damage to the leaves. It has been observed that members of the genus Aesculus are characterized by diverse susceptibility to C. ohridella. Four specimens of the Aesculus genus which differ in susceptibility to this leaf miner-Aesculus turbinata (susceptible), Aesculus $\times n e-$ glecta (resistant) and two specimens of Aesculus hippocastanum (relatively susceptible and relatively resistant)—were examined. The levels of substances which may function as attractants (chloroplast pigments, anthocyanins), deterrents or repellents (flavonols, phenols), or a source of nutrients (free $\alpha$-amino acids and carbohydrates) were determined in leaves of these four trees during two growing seasons. The results showed that the more pestsusceptible A. turbinata had, in both growing seasons, significantly higher levels of leaf carbohydrates and anthocyanins than the resistant Ae. $\times$ neglecta. Thus, anthocyanins and carbohydrates may be the traits which affect oviposition preference and favor the feeding of $C$. ohridella in the susceptible Ae. turbinata. The relatively susceptible specimen of Ae. hippocastanum contained
\end{abstract}

Communicated by H. Peng.

Hanna Bandurska

bandur@up.poznan.pl

1 Department of Plant Physiology, Poznań University of Life Sciences, Wołyńska 35, 60-637 Poznan, Poland

2 Department of Computer Science and Statistics, Poznan University of Medical Sciences, Dąbrowskiego 79, 60-529 Poznan, Poland

3 Department of Mathematical and Statistical Methods, Poznań University of Life Sciences, Wojska Polskiego 28, 60-637 Poznan, Poland slightly higher carbohydrate and anthocyanin levels than the relatively resistant one, but only in one growing season. Therefore, it does not explain the causes of their different susceptibility to the pest. The concentration of phenolics in the susceptible Ae. turbinata tree and the relatively susceptible Ae. hippocastanum individual was higher than in the resistant Ae. $\times$ neglecta and relatively resistant $A e$. hippocastanum, respectively. This may suggest that leaf phenolic composition, but not overall concentration, is responsible for different susceptibility of examined trees of Aesculus spp. to the horse-chestnut leaf miner. The present results also demonstrate that the determined chemical compounds do not constitute a complete description of the biochemical relationships between $C$. ohridella and the examined horse-chestnut trees.

Keywords Horse-chestnut - Cameraria ohridella .

Phenolics · Amino acids · Carbohydrates · Plant pigments

\section{Introduction}

For over 20 years, a threat to the esthetic values of horsechestnut has been posed by the inconspicuous moth horsechestnut leaf miner (Cameraria ohridella Deschka \& Dimić, Lepidoptera: Gracillariidae), which was first recorded in Macedonia in the 1970s and rapidly spread throughout Central and Western Europe (Valade et al. 2009). The economic cost arising from the protection of Aesculus trees against this pest is substantial. For example, in Germany current costs of five major urban centers range from $10,020,000$ to $33,800,000 €$ annually, but if trees in green spaces died, replacement costs would run up to 10.7 billion $€$ (Reinhardt et al. 2003). 
The species of the genus Aesculus are characterized by diverse susceptibility to $C$. ohridella. The main host of this pest is the white horse-chestnut (Aesculus hippocastanum L.), which is native to the Balkans and since the end of the sixteenth century has been introduced throughout Europe as an attractive ornamental tree (Prada et al. 2011). However, considerable variation in susceptibility to $C$. ohridella has been observed between Ae. hippocastanum individual trees (Straw and Tilbury 2006; Irzykowska et al. 2013). Also susceptible to $C$. ohridella is the Japanese horse-chestnut (Aesculus turbinata Blume). Resistant species include Aesculus indica (Wall. ex Camb.) Hook, Aesculus californica (Spach) Nutt., Aesculus parviflora Walter, Aesculus assamica Griff., and Aesculus wilsoni Rehder, which are of Asian and/or of North American origin (Straw and Tilbury 2006; D'Costa et al. 2013). Likewise, some species of North American origin (Aesculus sylvatica Bartram, Aesculus pavia L., Aesculus flava Aiton, Aesculus glabra Wild) are colonized by females that deposit eggs on the leaf surface but most larvae die during development (Kenis et al. 2003; Ferracini et al. 2010). Also resistant to C. ohridella is the hybrid of European Aesculus hippocastanum L. and American Aesculus pavia L. named red horse-chestnut (Aesculus $\times$ caenea Hayne), a popular tree in Europe (Irzykowska et al. 2013).

Resistance or susceptibility to pests is the result of plant-pest interaction. There are three mechanisms of resistance to herbivores, which are based on the plant properties. Antixenosis includes all plant traits which prevent oviposition and feeding and makes the plant an unsuitable host. Antibiosis involves harmful effects of plant on insect and tolerance that is the ability of plant to withstand or repair damage caused by the herbivore. The essential aspect of the relationships between host plants and insects is the chemical composition of leaves, which is decisive for the occurrence of interactions that facilitate or hamper feeding (Mithöfer and Boland 2012).

Plant-pest communication can take place through visual stimuli (Lev-Yadun and Gould 2009; Kocíková et al. 2012). The green leaf blades of host plants are willingly attacked by herbivores whose caterpillars feed on their tissues (Karageorgou and Manetas 2006). Chloroplast pigments are necessary for proper function of photosynthesis and are indirectly responsible for the synthesis of carbohydrates, which are a valuable nutrient for phytophagous insects (Jonas and Joern 2013). Female horse-chestnut leaf miners also react to the appearance of leaves and deposit their eggs on leaves with a large proportion of green area, which are not already occupied by mines, because such leaves have an abundance of food for larval growth and development (Johne et al. 2006a). The presence of anthocyanin pigments in leaves may also be a visual signal to insects (Archetti and Brown 2004). It was observed that red cabbage having a higher anthocyanin concentration than green cabbage was more attractive for caterpillars of lepidopteran pests (Coelho 2004). On the other hand, red coloration of leaves may also act as a warning signal for plant-eating insects, indicating that plants are well defended or have poor nutritional quality (Lev-Yadun and Gould 2009; Karageorgou and Manetas 2006; Maskato et al. 2014). High anthocyanin level may provide a visual cue to insect herbivores about a relatively high level of leaf total phenolic compounds which inhibit feeding of larvae and lead to their death (Karageorgou et al. 2008; Bouzouina et al. 2012; Oszmiański et al. 2014). In addition, feeding of herbivorous insect may induce accumulation of phenolics in leaves of host plants (Bernards and Båstrup-Spohr 2008). Chemical compounds that may act as defensive agents as well as alimentary deterrents are flavonols, which inhibit the growth of larvae, causing an extension of the larval period and increased larval mortality (Adeyemi et al. 2010; Martemyanov et al. 2012).

The availability of high quality and quantity of nutritional compounds (proteins, carbohydrates) is also an essential factor in the feeding of many herbivorous insects (Zhang et al. 2011). Good nutrition is necessary for the longevity of oviposition period, lifetime fecundity and oviposition rate in Lepidoptera (Cahenzli and Erhardt 2013; Marchioro and Foerster 2013). Plant amino acids are a key source of nitrogen, which is a significant factor in egg production (Cahenzli and Erhardt 2013). Carbohydrates, which are also an important component in the diet of many Lepidoptera, cover energy requirements and provide carbon skeletons for somatic development, fitness and reproductive output (Glendinning et al. 2007; Marchioro and Foerster 2013). High activity of amylase, maltase and saccharase which was found in the midgut of $C$. ohridella suggests that starch, maltose and saccharose are primary carbohydrate components of their diet (Stygar et al. 2010).

The aim of the study was to examine the content of chemical compounds which may act as attractants (chloroplast pigments, anthocyanins), defensive substances (anthocyanins, phenols and flavonols) and nutrients (free $\alpha$-amino acids and carbohydrates) in four Aesculus trees differing in susceptibility to $C$. ohridella. The research was focused on Japanese horse-chestnut (Aesculus turbinata), which is susceptible to this pest, resistant painted buckeye horse-chestnut (Aesculus $\times$ neglecta var. lanceolata Sargent, also known as Aesculus sylvatica Bartram), and two white horse-chestnut (Aesculus hippocastanum) trees that are growing close to each other and are not equally susceptible to this pest. One of them was colonized by the pest earlier, and the leaves are damaged to a greater extent than on the other tree.

These studies were undertaken in order to clarify the differences in resistance of the examined horse-chestnut trees to $C$. ohridella that we have observed for several years. According to the literature data, we assume that 
horse-chestnut trees not infested or those on which the leaf miner does not continue feeding contain compounds acting harmfully on the pest population and do not contain nutritional compounds for this pest (Johne et al. 2006b; Kropczyńska-Linkiewicz et al. 2008). On the other hand, trees inhabited by $C$. ohridella are likely to contain substances working as attractants that make it easier for the insect to find the host plant and may have adequate quantity and quality of nutritional compounds (Johne et al. 2006a; Kropczyńska-Linkiewicz et al. 2008; Svatos et al. 2009; Marchioro and Foerster 2013). The differences in the chemical composition of the leaves of these Aesculus trees will allow the identification of substances which may be important in the interaction between $C$. ohridella and these trees. The obtained results can be used for further phytochemical studies on larger populations of horse-chestnut species.

\section{Materials and methods}

\section{Weather data}

Data on weather conditions in the successive years of study were obtained from the website of Poznań University of Life Sciences (http://www.au.poznan.pl/wogr/hobo/index. html). The measurements were performed by the meteorological Onset HOBO Weather Station installed in the Experimental Station of Poznań University of Life Sciences. Results are presented as means for each month in the period from March to October.

\section{Plant material and sample collection}

Four trees of the genus Aesculus were included in this study: two Aesculus hippocastanum trees growing at the campus of Poznań University of Life Sciences, one tree of Ae. turbinata and one of Ae. $\times$ neglecta, both located in the Botanical Garden of the Adam Mickiewicz University. Fully developed compound leaves were randomly chosen from the same location within the tree crown (similarly lighted place at the same height of each tree crown) every 14 days, at the same time of day (between 8 and 9 am) from May to September 2011 and 2012. Collected material was put into plastic bags and transferred to the laboratory within 30-60 min. Sample collection and laboratory assessment were carried out by two persons.

\section{Estimation of damage of leaves by horse-chestnut leaf miner}

The degree of leaf damage was evaluated visually by the same person by estimating the size of leaf blade occupied by mines in relation to the total leaf area and was expressed in percentages. Each time the assessment was performed on 15 compound leaves from each tree. After assessment the leaves were used for chemical analyses.

\section{Chemical analyses}

The content of chloroplast pigments in leaves was determined immediately after transfer to the laboratory. Plant material for the determination of other compounds was frozen in liquid nitrogen and stored at $-20{ }^{\circ} \mathrm{C}$ until analysis. Only green parts of leaves (not occupied by mines) were taken for all evaluations. Chemical analyses were done during the entire growing season in the resistant $A e . \times n e-$ glecta tree and the relatively resistant Ae. hippocastanum individual in both 2011 and 2012 and in the susceptible Ae. turbinata tree in 2012. However, on the sampling dates in which more than $60 \%$ of the leaf blade was occupied by mines chemical analyses were not carried out (Ae. turbinata tree from 14 July 2011, relatively susceptible Ae. hippocastanum tree from 14 July 2011 and 13 August 2012).

Each parameter measured for each tree, date and year was estimated in five independent replications. Each replication was a sample of plant material which derived from the middle leaflet of different compound leaves collected from the same tree.

\section{Chloroplast pigments}

Total chlorophyll and carotenoids content was estimated according to the method of Hiscox and Israelstam (1979). Leaf samples $(100 \mathrm{mg}$ ) were cut into pieces and pigments were extracted at $65{ }^{\circ} \mathrm{C}$ using $5 \mathrm{~cm}^{3}$ of dimethyl sulfoxide (DMSO). Optical density of the extract was measured at 480, 649 and $663 \mathrm{~nm}$. The content of total chlorophyll and carotenoids was calculated following the modified Arnon equations (Wellburn 1994) and was expressed in milligrams per gram of fresh weight $\left(\mathrm{mg} \mathrm{g}^{-1} \mathrm{FW}\right)$.

\section{Anthocyanins}

Plant material $\left(500 \mathrm{mg}\right.$ ) was homogenized with $3 \mathrm{~cm}^{3}$ of $0.5 \mathrm{~N} \mathrm{HCl}$, and centrifuged at $6000 \mathrm{~g}$ for $10 \mathrm{~min}$. Absorbance of the supernatant was measured at $530 \mathrm{~nm}$ (Wang et al. 2000). Anthocyanin content in leaf tissue was calculated using a calibration curve of cyanine chloride and was expressed in micrograms per gram of fresh weight $\left(\mu \mathrm{g} \mathrm{g}^{-1} \mathrm{FW}\right)$.

\section{Total phenolic compounds}

Leaf samples $(250 \mathrm{mg})$ were cut into small pieces and extracted at $60{ }^{\circ} \mathrm{C}$ first with $5 \mathrm{~cm}^{3}$ of $96 \%$ ethanol for 
$3 \mathrm{~min}$ and then with $5 \mathrm{~cm}^{3}$ of $65 \%$ ethanol for $5 \mathrm{~min}$. Each extract was poured into a test tube and it was filled up to the final volume of $10 \mathrm{~cm}^{3}$. To $0.5 \mathrm{~cm}^{3}$ of extract $0.1 \mathrm{~cm}^{3}$ of Folin-Denis reagent was added and exactly 3 min later $1 \mathrm{~cm}^{3}$ of $10 \% \mathrm{Na}_{2} \mathrm{CO}_{3}$. After $20 \mathrm{~min}$ the absorbance was measured at $660 \mathrm{~nm}$ (Swain and Hillis 1959). The level of phenolics was calculated from the standard curve for coumaric acid and expressed in micrograms per gram of fresh weight $\left(\mu \mathrm{g} \mathrm{g}^{-1} \mathrm{FW}\right)$.

\section{Flavonols}

Leaf samples (500 mg) were cut into small pieces and homogenized with $5 \mathrm{~cm}^{3}$ of methanol, $\mathrm{HCl}$ and distilled water $(90: 1: 1, \mathrm{v} / \mathrm{v} / \mathrm{v})$. The solution was stirred and heated $\left(60{ }^{\circ} \mathrm{C}\right.$ ) for $10 \mathrm{~min}$, cooled at room temperature for $15 \mathrm{~min}$ and centrifuged at $6000 \mathrm{~g}$ for $30 \mathrm{~min}$ (Day 1993). The absorbance of the supernatant was measured at $254 \mathrm{~nm}$ with a UV/visible spectrophotometer (Jasco V-530 UVVIS Spectrophotometer). Flavonol content in leaf tissue was calculated using the calibration curves of quercetin (Stefova et al. 2001) and was expressed in micrograms per gram of fresh weight ( $\left.\mu \mathrm{g} \mathrm{g}^{-1} \mathrm{FW}\right)$.

\section{Free $\alpha$-amino acids}

The ninhydrin method was applied to estimate the level of amino acids (Baily 1962). Leaf samples (250 mg) were cut into small pieces and homogenized with $3 \mathrm{~cm}^{3}$ of ethanol. The homogenate was centrifuged at $6000 \mathrm{~g}$ for $30 \mathrm{~min} .0 .1 \mathrm{~cm}^{3}$ of the supernatant was mixed with $0.9 \mathrm{~cm}^{3}$ of $0.4 \mathrm{M}$ acetic acid buffer, $\mathrm{pH} 5$ and $1 \mathrm{~cm}^{3}$ of ninhydric reagent $\left(2 \mathrm{~g}\right.$ of ninhydrin $+50 \mathrm{~cm}^{3}$ of $50 \%$ ethanol). The mixture was incubated at $100{ }^{\circ} \mathrm{C}$ for $15 \mathrm{~min}$ and then cooled. The absorbance of samples was determined at $570 \mathrm{~nm}$. Amino acid content in leaf tissue was calculated using the calibration curves of alanine and was expressed in micrograms per gram of fresh weight $\left(\mu \mathrm{g} \mathrm{g}^{-1} \mathrm{FW}\right)$.

Table 1 Weather conditions from March to October (monthly means) during 2011 and 2012

\section{Total soluble carbohydrates}

The anthrone colorimetric method was applied to measure carbohydrate content (Luo and Huang 2011). Leaf samples (250 $\mathrm{mg}$ ) were cut into small pieces and extracted for $30 \mathrm{~min}$ at $60{ }^{\circ} \mathrm{C}$ using $4 \mathrm{~cm}^{3}$ of $80 \%$ ethanol. $0.5 \mathrm{~cm}^{3}$ of supernatant was mixed with $1 \mathrm{~cm}^{3}$ of anthrone reagent $\left(25 \mathrm{~cm}^{3} \mathrm{H}_{2} \mathrm{SO}_{4}+5 \mathrm{mg}\right.$ anthrone reagent). After $15 \mathrm{~min}$ the absorbance of the colored reaction product was read at $620 \mathrm{~nm}$. The amount of carbohydrates was calculated using a standard curve for glucose and was expressed in milligrams per gram of fresh weight $\left(\mathrm{mg} \mathrm{g}^{-1} \mathrm{FW}\right)$.

\section{Statistical analysis}

For evaluation of statistical differences between the analyzed individual trees of two species (Ae. turbinata vs. Ae. $\times$ neglecta) and two trees of the same species (Ae. hippocastanum) we used analysis of variance (ANOVA) with repeated measurements $(n=5)$, where the dependent variables were the data of successive sampling dates and independent variables were individual trees. All statistical analyses were conducted for the same number of sampling dates. The significance level was set at $\alpha=0.05$. The differences were considered as statistically significant when $p$ values were less than or equal to $\alpha$. All numerical analyses were performed using the STATISTICA 10 package.

\section{Results}

\section{Weather conditions}

The weather conditions were slightly different in 2011 and 2012. The average precipitation was higher in 2012, mainly due to higher precipitation in the period from May to August (Table 1). The average humidity was at similar levels for most months in 2011 and 2012, except for June, when it was much lower in 2011 than in 2012. The

\begin{tabular}{|c|c|c|c|c|c|c|c|c|}
\hline \multirow[t]{2}{*}{ Month } & \multicolumn{2}{|c|}{ Temperature $\left({ }^{\circ} \mathrm{C}\right)$} & \multicolumn{2}{|c|}{ Insolation (h) } & \multicolumn{2}{|c|}{ Precipitation (mm) } & \multicolumn{2}{|c|}{ Humidity (\%) } \\
\hline & 2011 & 2012 & 2011 & 2012 & 2011 & 2012 & 2011 & 2012 \\
\hline March & 3.7 & 6.0 & 153.2 & 140.0 & 16.2 & 11.2 & 73.9 & 76.3 \\
\hline April & 14.6 & 10.9 & 173.7 & 196.2 & 7.2 & 16.4 & 63.7 & 68.7 \\
\hline May & 12.0 & 15.6 & 241.3 & 241.9 & 9.4 & 47.6 & 62.4 & 63.9 \\
\hline June & 18.7 & 16.2 & 226.4 & 161.3 & 55.0 & 94.4 & 65.4 & 75.6 \\
\hline July & 16.7 & 19.3 & 86.0 & 199.0 & 146.4 & 126.2 & 80.4 & 76.3 \\
\hline August & 18.8 & 18.7 & 201.7 & 179.8 & 17.4 & 33.4 & 75.2 & 75.6 \\
\hline September & 15.1 & 14.4 & 169.3 & 143.7 & 30.0 & 20.6 & 78.1 & 78.3 \\
\hline October & 8.8 & 10.0 & 85.6 & 81.2 & 20.6 & 18.0 & 86.1 & 84.0 \\
\hline
\end{tabular}




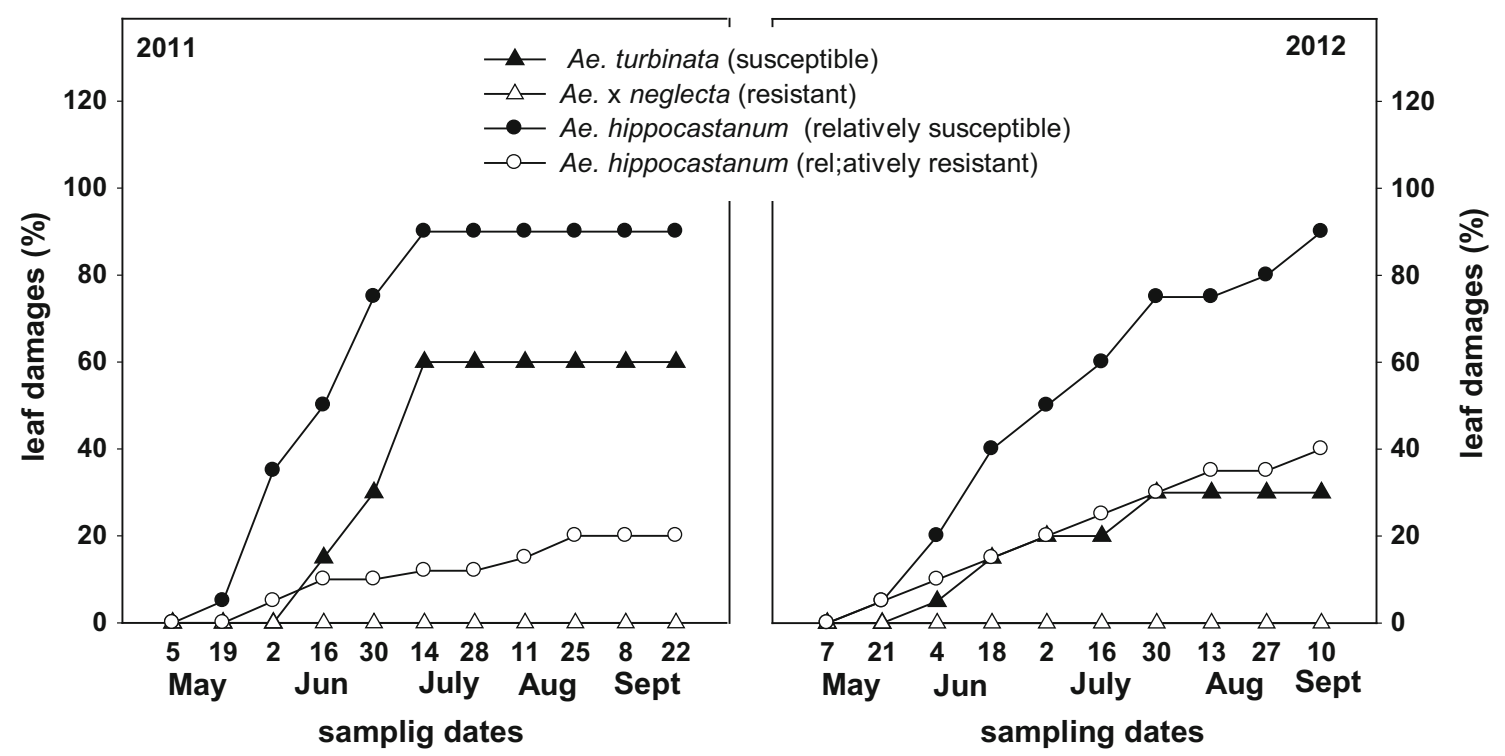

Fig. 1 The damage of leaf blades in Japanese horse-chestnut (Aesculus turbinata), painted buckeye (Aesculus $\times$ neglecta) and two trees of white horse-chestnut (Aesculus hippocastanum) in years 2011 and 2012

insolation measured on the basis of the number of sunny hours in 2011 was higher than in 2012 in five months (March, June, August, September and October), but in May it was similar in these two years. The average air temperature was lower in March and July, and higher in June, in 2011 in comparison to the same months in 2012, being at similar levels in the other months in both years.

\section{Damage of leaves by the horse-chestnut leaf miner}

In both years, greater damage of leaves was found in the relatively susceptible individual of Ae. hippocastanum. Similarly, the susceptible Ae. turbinata was characterized by greater damage than the resistant $A e . \times$ neglecta (Fig. 1). Moreover, in the relatively susceptible Ae. hippocastanum tree and susceptible Ae. turbinata earlier and greater damage of leaf blades was found in 2011 than in 2012. This effect was probably caused by 2 -week-earlier start of feeding by the pest in 2011 than in 2012. Already in mid-July 2011, almost $90 \%$ of the leaf blade area was covered with mines in the relatively susceptible tree of $A e$. hippocastanum, and 60\% in Ae. turbinata. In 2012 at the beginning of September $90 \%$ damage of the leaf blades was observed in the relatively susceptible white horse-chestnut tree and only $30 \%$ in Ae. turbinata. The leaf blades of resistant Ae. $\times$ neglecta were inhabited by single females but symptoms of feeding were never observed.

\section{Results of chemical analyses}

Statistically significant differences in the level of all estimated compounds throughout both years of experiments were observed between resistant Ae. $\times$ neglecta and susceptible Ae. turbinata (Table 2). In leaves of Ae. $\times$ neglecta higher levels of chlorophyll, carotenoids and $\alpha$ amino acids were observed, while in Ae. turbinata there were higher levels of anthocyanins, phenols, flavonols and carbohydrates. Moreover, there were significant differences in time-dependent changes in the level of almost all examined compounds in these species, with the exception of chlorophyll in 2011 and carbohydrate and amino acids in 2012. In the two white horse-chestnut trees statistically significant differences were found only in the level of chlorophyll, anthocyanins, phenolics and flavonols, which were higher in the tree relatively susceptible to this pest (Table 3). The changes in the levels of chlorophyll, carotenoids and anthocyanins in these trees proceeded differently in time, in 2011. However, in 2012 different timedependent changes were revealed in the level of almost all examined compounds with the exception of carotenoids and anthocyanins. The contents of particular compounds in the leaves of examined trees on successive sampling dates in 2011 and 2012 are shown in Figs. 2, 3, 4, 5, 6, 7, and 8.

Both in 2011 and 2012, the pest-resistant Ae. $\times$ neglecta was characterized by significantly higher total chlorophyll content in the leaf blades compared to susceptible Japanese horse-chestnut (Fig. 2). Likewise, in the leaves of the relatively resistant Ae. hippocastanum total chlorophyll content in both 2011 and 2012 was significantly higher than in the relatively susceptible one. However, these differences occurred only from mid-May to mid-June (Fig. 2).

Throughout the 2011 growing season the carotenoid content in the leaf blades of $A e . \times$ neglecta was 

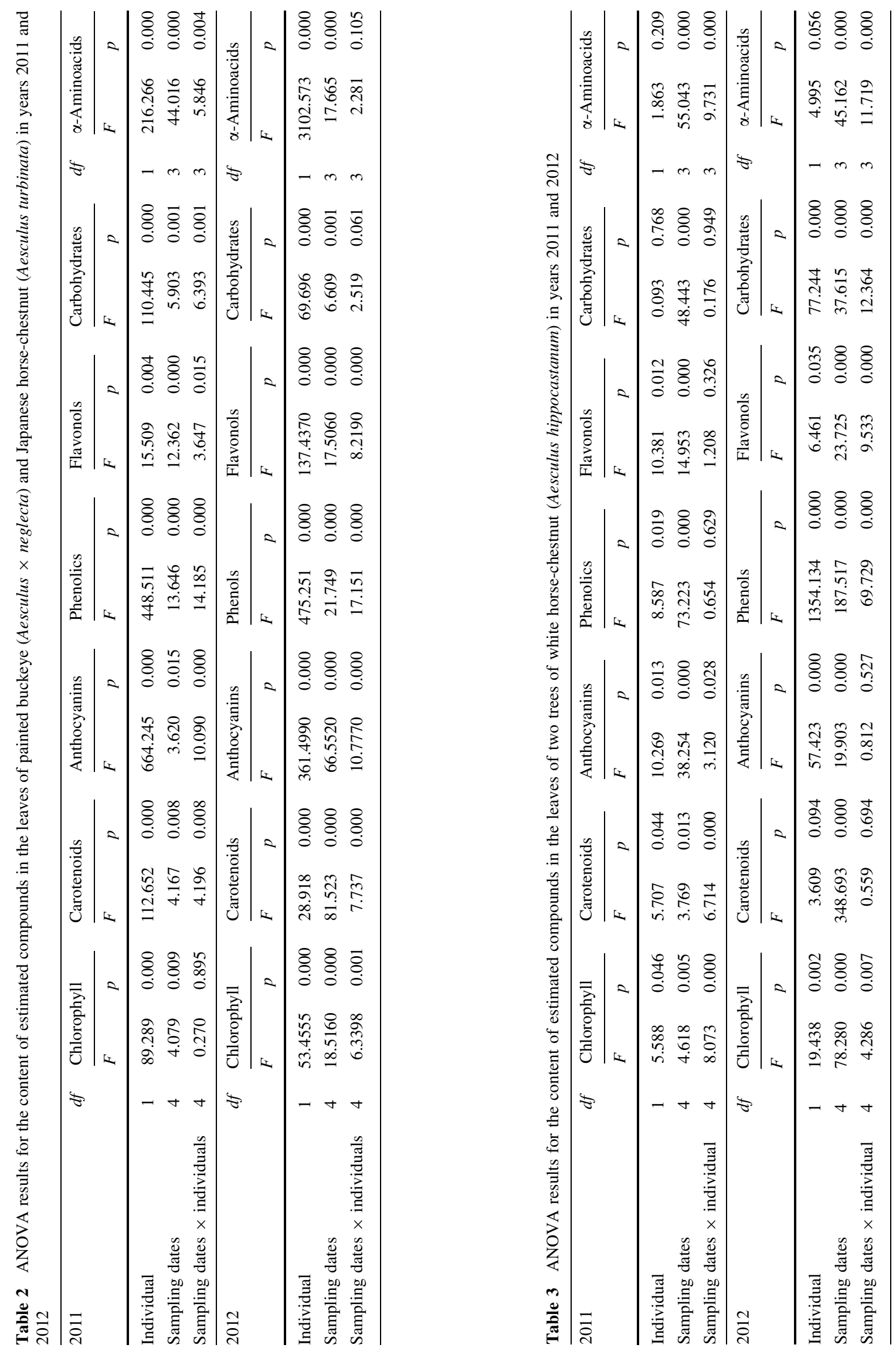


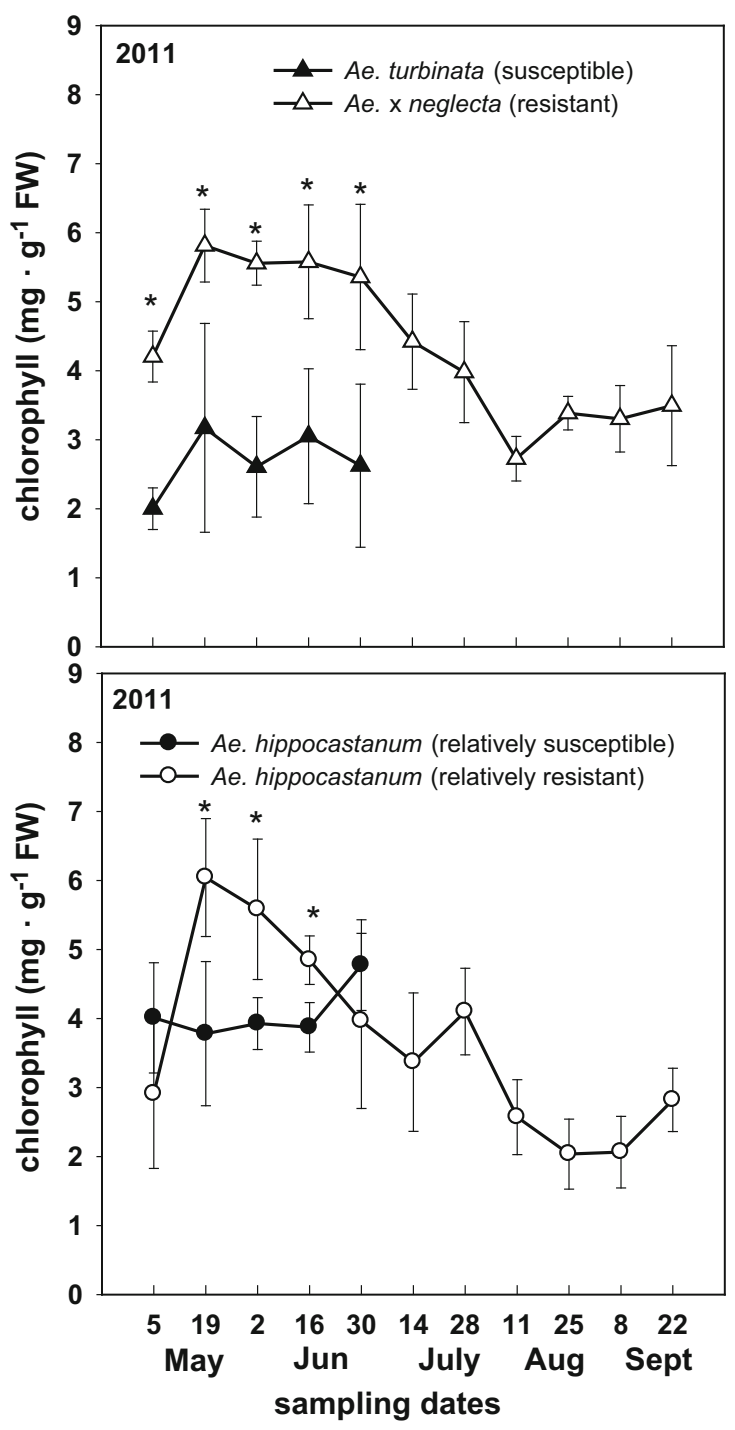

Fig. 2 Level of total chlorophyll in leaf blades of Japanese horsechestnut (Aesculus turbinata), painted buckeye (Aesculus $\times$ neglecta) and two trees of white horse-chestnut (Aesculus hippocastanum) in

significantly higher than in susceptible Ae. turbinata (Table 2; Fig. 3). By contrast, although in 2012 the differences between these Aesculus trees in the level of carotenoid pigments were statistically significant (Table 2), they were lower than in 2011 (Fig. 3). The level of carotenoids in leaves of Ae. $\times$ neglecta was higher than Ae. turbinata but only on four sampling dates (21 May, 4 June, 30 July and 13 August). In the leaves of the resistant $A e$. hippocastanum tree in 2011 a slightly higher carotenoid level was observed than in the relatively susceptible one. However, in 2012 there was no difference in the level of these compounds between examined white horse-chestnut trees (Fig. 3).

The pest-susceptible Ae. turbinata was characterized by a higher level of anthocyanins than resistant Ae. × neglecta, both in 2011 and 2012 (Fig. 4). A slight differences in the

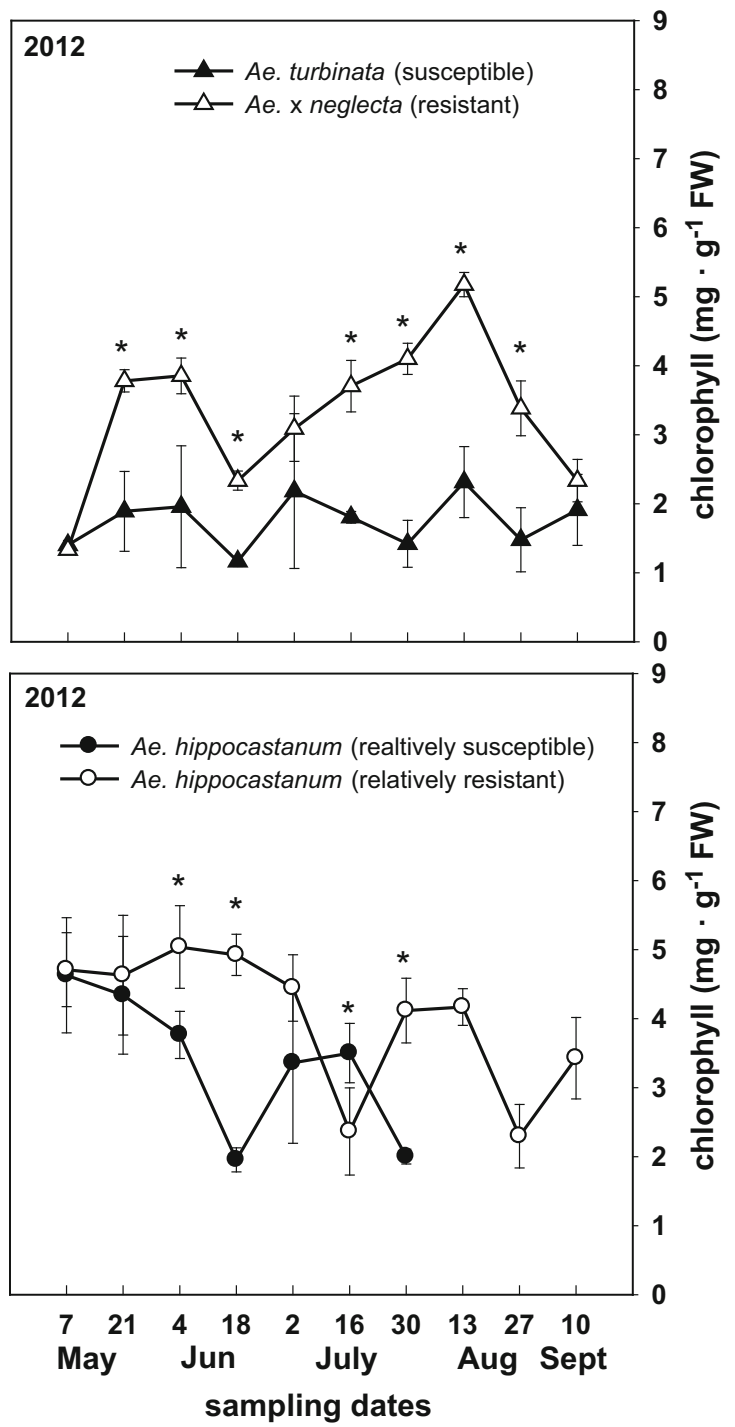

years 2011 and 2012. Data are the means of five replications \pm standard deviation marked as vertical bars. Significant differences between genotypes at the sampling dates are marked as asterisk

level of these pigments between the two Ae. hippocastanum trees differing in susceptibility to this pest were found in 2011 and 2012, but only on two or three dates (Fig. 4).

The content of phenolic compounds in 2011 and 2012 was significantly higher in the leaves of susceptible $A e$. turbinata than resistant Ae. $\times$ neglecta (Fig. 5). Similarly, a higher level of these compounds was observed in the leaves of the pest-susceptible Ae. hippocastanum tree compared to the relatively resistant one (Fig. 5). Furthermore, the content of phenolic compounds in resistant Ae. $\times$ neglecta remained at a similar level at successive dates of determination. In $A e$. turbinata and both specimens of Ae. hippocastanum their level increased in the course of feeding. It should be noted that the Ae. hippocastanum tree relatively resistant to horsechestnut leaf miner was characterized by a twofold higher level of phenolic compounds in 2011 than in 2012. This 

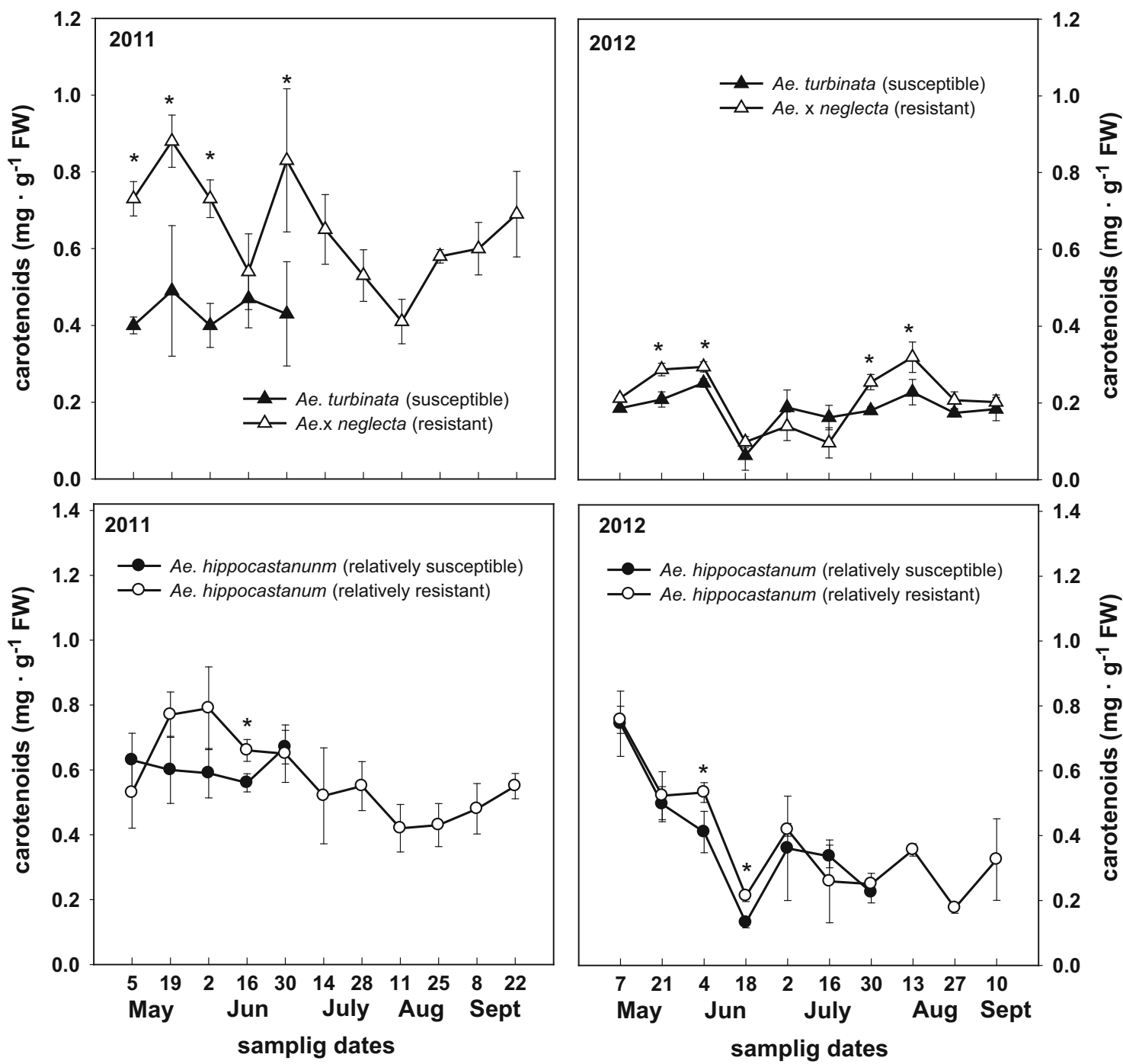

1.2

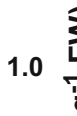

$\frac{3}{1}$

0.8

동

Fig. 3 Level of carotenoids in leaf blades of Japanese horse-chestnut (Aesculus turbinata), painted buckeye (Aesculus $\times$ neglecta) and two trees of white horse-chestnut (Aesculus hippocastanum) in 2011 and

2012. Data are the means of five replications \pm standard deviation marked as vertical bars. Significant differences between genotypes at the sampling dates are marked as asterisk

could be associated with the more rapid development of the pest in 2012.

In 2011 a slightly higher level of flavonols but only on two dates was observed in the leaves of Ae. turbinata compared to Ae. $\times$ neglecta, whereas in 2012 these differences were larger, found on four dates (Fig. 6). Similarly, the pest-susceptible Ae. hippocastanum was characterized by a higher level of flavonols than the relatively resistant tree of this species and the observed differences were more pronounced in 2012 than in 2011 (Fig. 6).

In both years of experiments $\alpha$-amino acid content was slightly higher in the resistant Ae. $\times$ neglecta than the susceptible Ae. turbinata (Fig. 7). There were no significant differences in the levels of these compounds between the two examined Ae. hippocastanum trees in 2011. However, in 2012 a slightly higher level of $\alpha$-amino acids

was observed in the relatively resistant Ae. hippocastanum tree (Fig. 7).

In 2011 as well as in 2012 the level of carbohydrates was significantly higher in susceptible Ae. turbinata than resistant Ae. $\times$ neglecta (Fig. 8). Leaf carbohydrate content in both Ae. hippocastanum trees was at the same level in 2011 but at most dates throughout 2012 was significantly higher in the relatively susceptible tree (Fig. 8).

\section{Discussion}

Weather conditions (air humidity, sunlight and temperature) are basic factors that influence phytophagous insects directly and indirectly (Jaworski and Hiszczanski 2013). Temperature exerts a significant effect on the development 


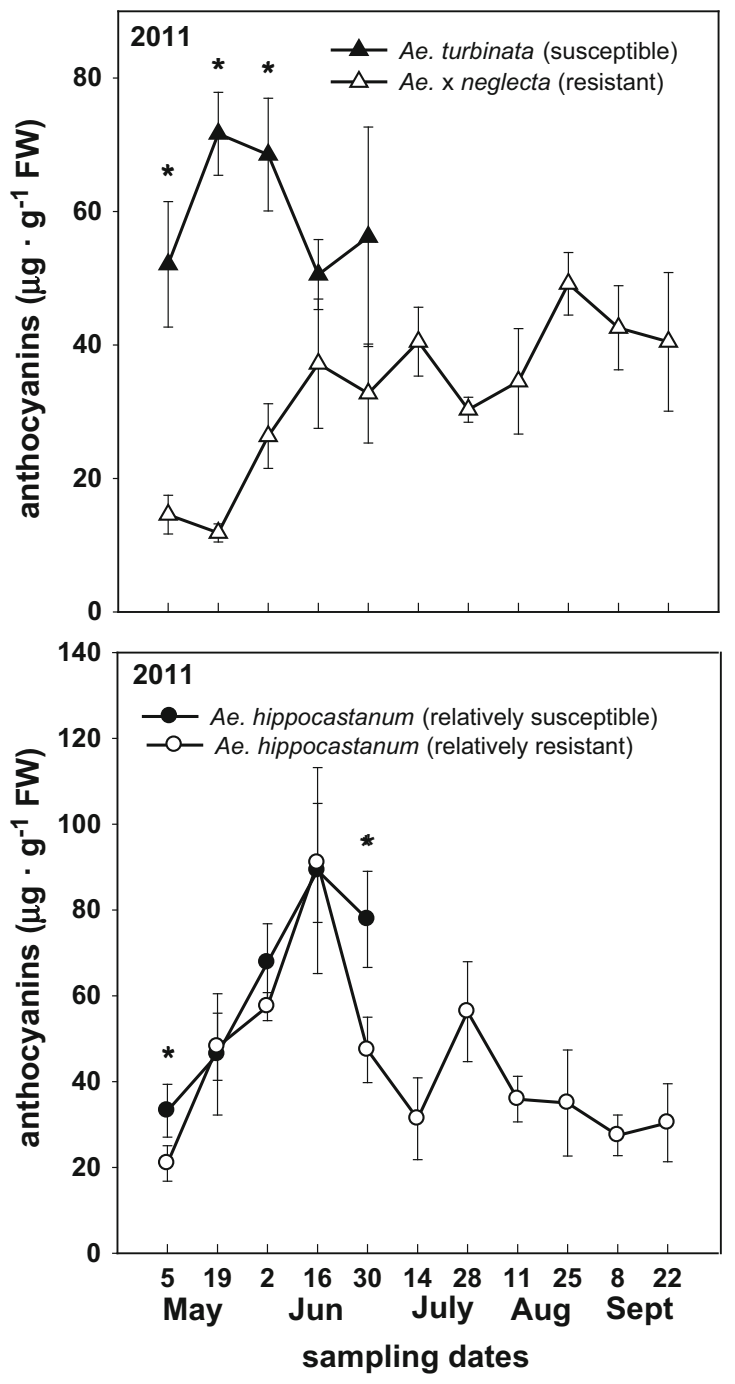

Fig. 4 Level of anthocyanins in leaf blades of Japanese horsechestnut (Aesculus turbinata), painted buckeye (Aesculus $\times$ neglecta) and two trees of white horse-chestnut (Aesculus hippocastanum) in

of C. ohridella (Dimić et al. 2000). Depending on climate conditions, the horse-chestnut leaf miner produces two to four generations per year. Usually in a warm dry summer C. ohridella is able to complete three generations (Tilbury et al. 2004; Girardoz et al. 2007). The flight period of the adults emerging from overwintering pupae (first generation) begins at the end of April and the beginning of May. The second generation usually appears in June-July and the third in August-September (Kukula-Mlynarczyk and Hurej 2007; Pál et al. 2014) The final generation overwinters in the stage of pupae, which are known to be extremely frost tolerant and survive in the fallen leaves (Tomiczek and Krehan 1998; Pál et al. 2014). It was reported that the density of the first and second generation of $C$. ohridella moths was greater during a warm than during a cool summer, which resulted in greater damage of horse-chestnut leaves (Kukuła-Młynarczyk and Hurej 2007).

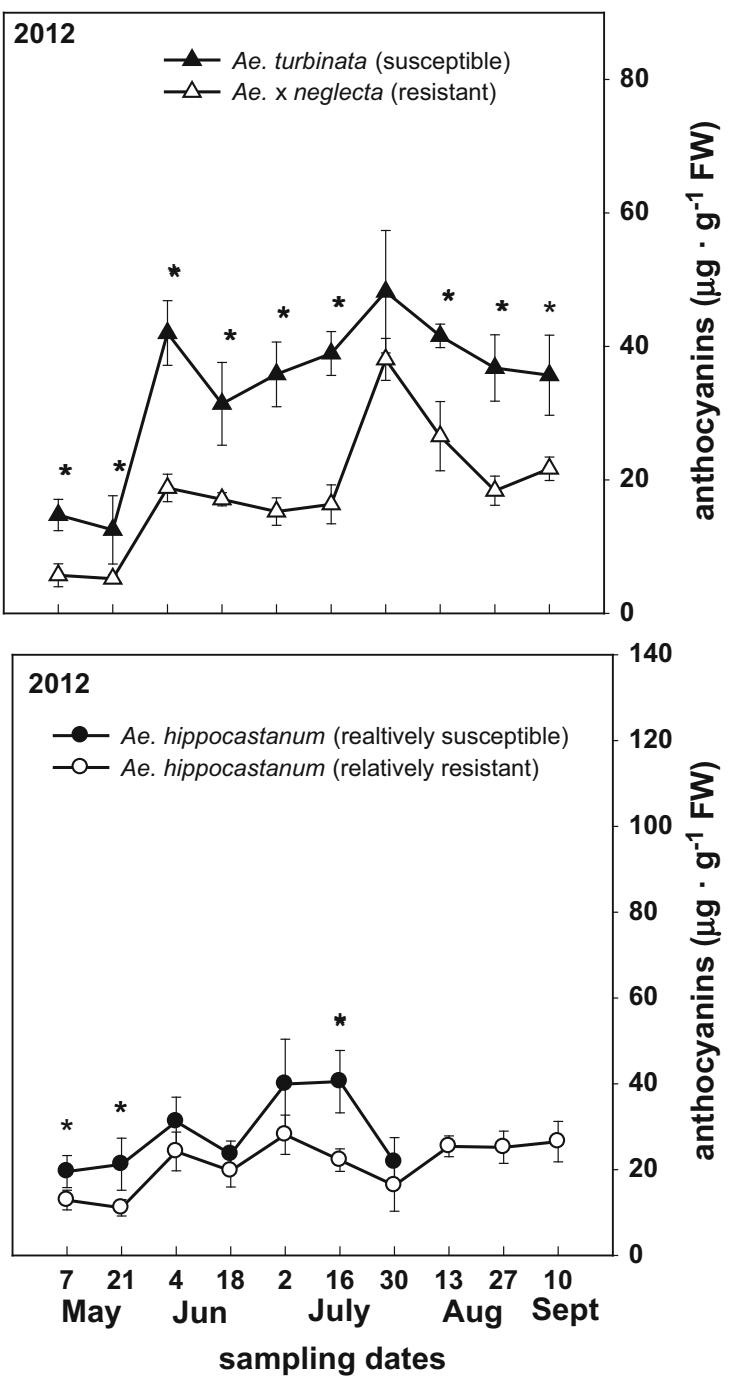

2011 and 2012. Data are the means of five replications \pm standard deviation marked as vertical bars. Significant differences between genotypes at the sampling dates are marked as asterisk

However, during a cool summer only two generations were developed and less damage of leaves was observed (Girardoz et al. 2007). Our research has shown that horsechestnut individuals more susceptible to the pest were characterized by greater damage of leaves in 2011 than in 2012. This could be a result of slightly higher air temperature in April and June of 2011 than 2012, this being the period of larval development and emergence of the adults of the first and second generation.

A substantial influence on the behavior of insects is exerted by chemical composition of the host plants (Johne et al. 2006c; Johne et al. 2008; D'Costa et al. 2014). The reciprocal ratio of plant pigments contained in the leaf blades determines the final color of these organs and constitutes a visual signal which facilitates adult Lepidoptera to locate the host plant (Kočíková et al. 2012). The present results revealed that total chlorophyll content in the leaves 

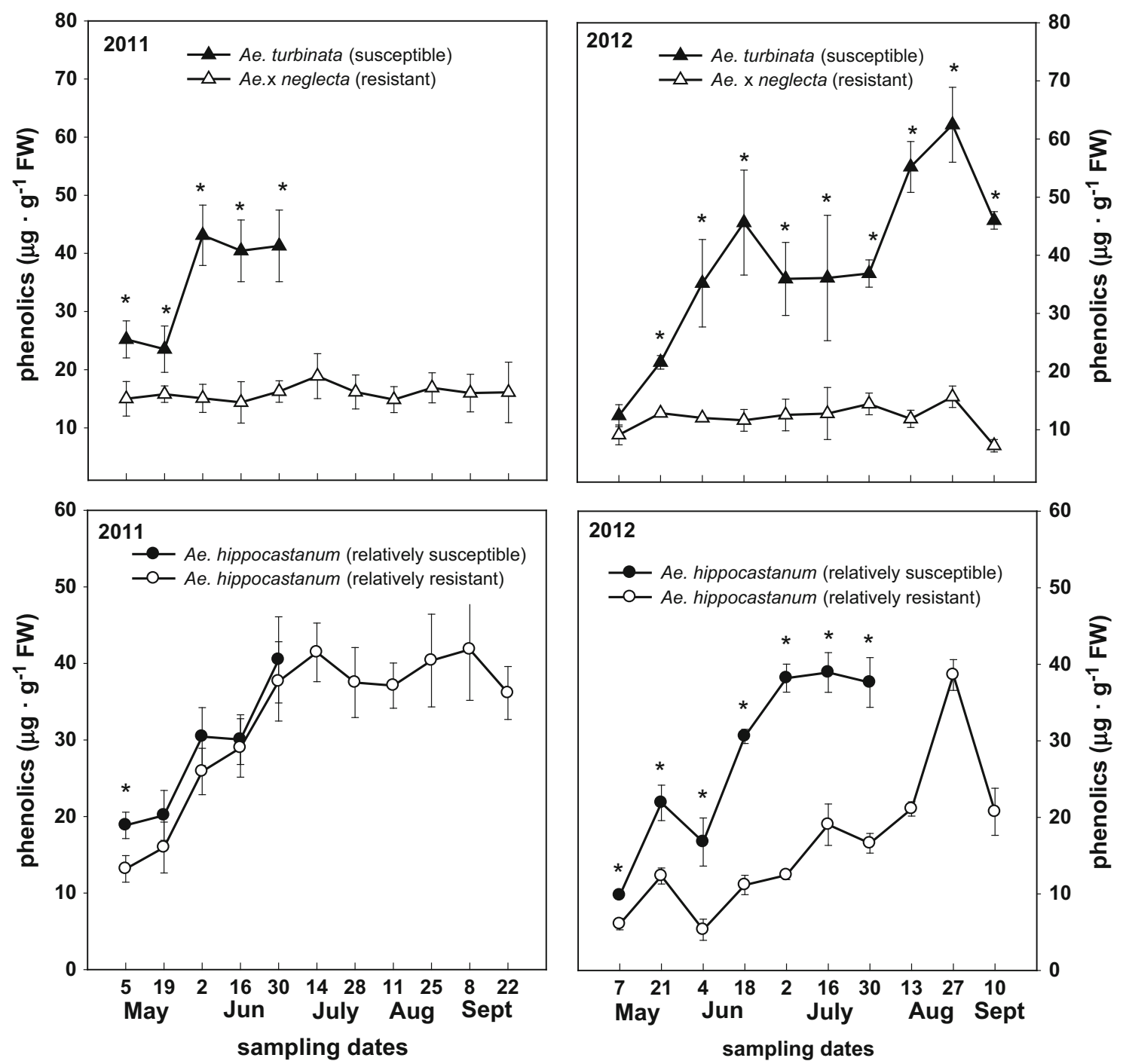

Fig. 5 Level of phenols in leaf blades of Japanese horse-chestnut (Aesculus turbinata), painted buckeye (Aesculus $\times$ neglecta) and two trees of white horse-chestnut (Aesculus hippocastanum) in 2011 and

of Ae. $\times$ neglecta completely resistant to C. ohridella was significantly higher than in Ae. turbinata, which is occupied by this pest. Similarly, higher leaf chlorophyll level in the relatively resistant tree of Ae. hippocastanum was coincident with the period in which it was less colonized by the horse-chestnut leaf miner than the susceptible one. This could mean that the intense green color of the leaves does not correspond to the visual pattern responsible for the location of host plants by the pest moths. On the other hand, Johne et al. (2006a) observed that the females of horse-chestnut leaf miner deposit more eggs on green leaf blades than on those which are covered by mines, because the oviposition and larval mining cause changes in the profile of leaf volatile compounds and odor pattern of leaves which inhibit other individuals from oviposition on the same leaves.

2012. Data are the means of five replications \pm standard deviation marked as vertical bars. Significant differences between genotypes at the sampling dates are marked as asterisk

It should be noted that Ae. turbinata susceptible to $C$. ohridella was characterized by a higher level of anthocyanins in leaf blades than Ae. $\times$ neglecta on all of the dates in both growing seasons. The content of these pigments was higher at the beginning of the growing season before the appearance of the larvae. Therefore, it can be assumed that a higher level of these red pigments affects leaf coloration, recognized as a visual stimulus by females of horse-chestnut leaf miner looking for a place to deposit eggs. Similarly, the Brassica rapa genotype which was characterized by high concentrations of anthocyanins was more attacked by herbivorous insects than green leaf genotypes (Coelho 2004). On the other hand, there are numerous reports showing that higher levels of these pigments may inhibit infestation of leaves (Karageorgou and Manetas 2006; Karageorgou et al. 2008; Lev-Yadun and 

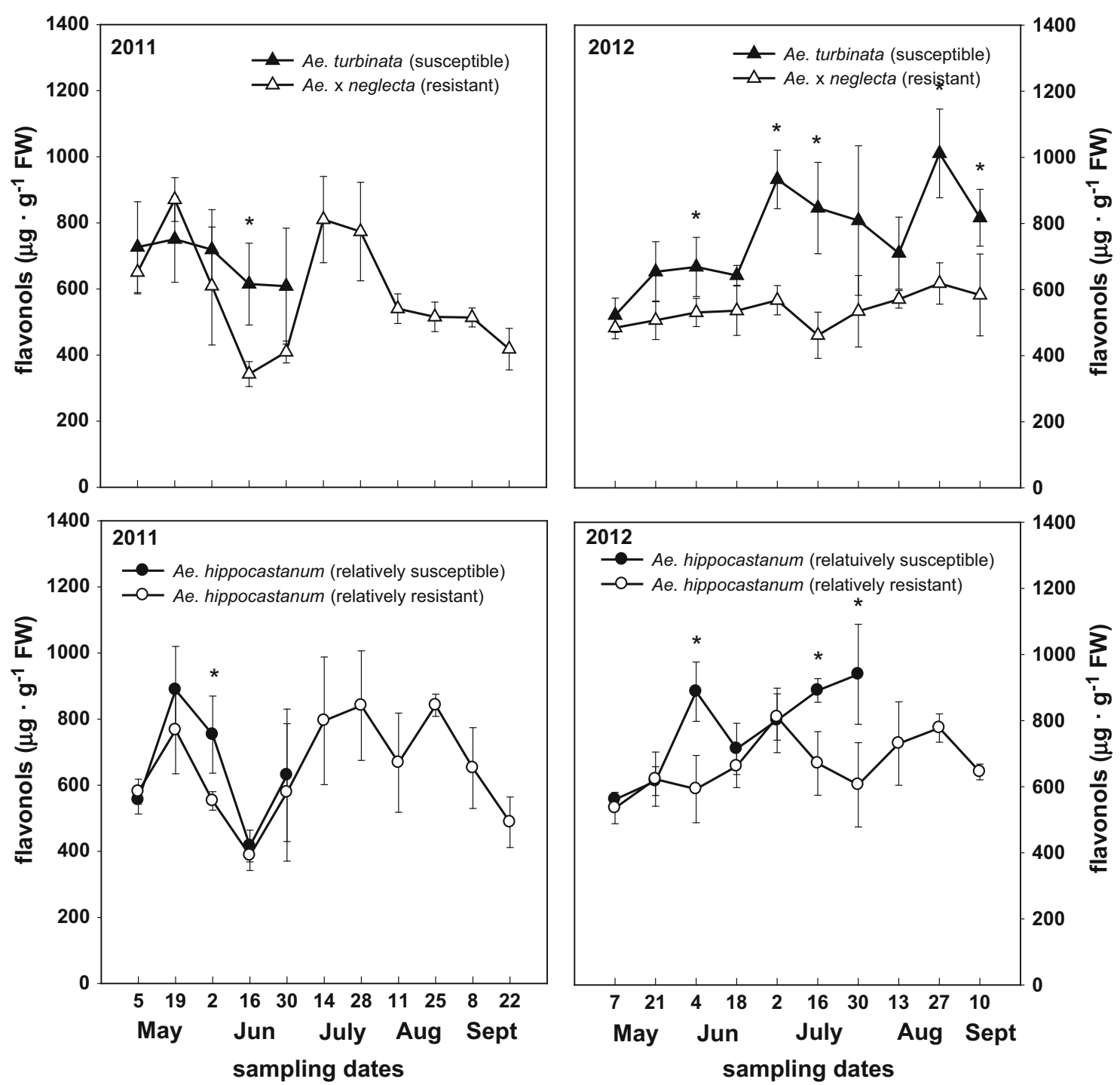

Fig. 6 Level of flavonols in leaf blades of Japanese horse-chestnut (Aesculus turbinata), painted buckeye (Aesculus $\times$ neglecta) and two trees of white horse-chestnut (Aesculus hippocastanum) in 2011 and

Gould 2009). Karageorgou and Manetas (2006) believe that insects avoid leaves rich in anthocyanins because they usually contain a lot of phenolics which act as defensive compounds. In fact, the results show that leaves of $A e$. turbinata more abundant in anthocyanins contained significantly more phenolics than Ae. $\times$ neglecta, but these compounds did not affect the pests adversely because larvae developed well on this species. These results did not confirm the hypothesis that anthocyanins are compounds which may offer increased protection against phytophages. The results of some other studies also indicate that foliar anthocyanins are not toxic to insect herbivores and do not inhibit feeding (Schaefer and Rolshausen 2006).

Among the secondary metabolites, plant phenolic compounds represent a very important group of defensive

2012. Data are the means of five replications \pm standard deviation marked as vertical bars. Significant differences between genotypes at the sampling dates are marked as asterisk

compounds which play an essential role in resistance to insect herbivores (Ossipov et al. 2001; War et al. 2012). The enhancement of phenolic acids was observed in Archis hypogaea $\mathrm{L}$. infested with three different Lepidoptera pests (Sambangi and Usha Rani 2013). A rapid induced defense response caused by an increased concentration of simple phenolics and monoterpenes was observed in silver birch infested by Lymantria dispar (Martemyanov et al. 2012). In our study the concentration of phenolics in the leaf blades of Ae. turbinata as well as in both individuals of Ae. hippocastanum increased with the development of the pest, which could be considered as a manifestation of chemical defense against feeding. It seems that these horse-chestnut trees expressly defended themselves but it was ineffective. It probably results from the fact that $C$. ohridella has an 

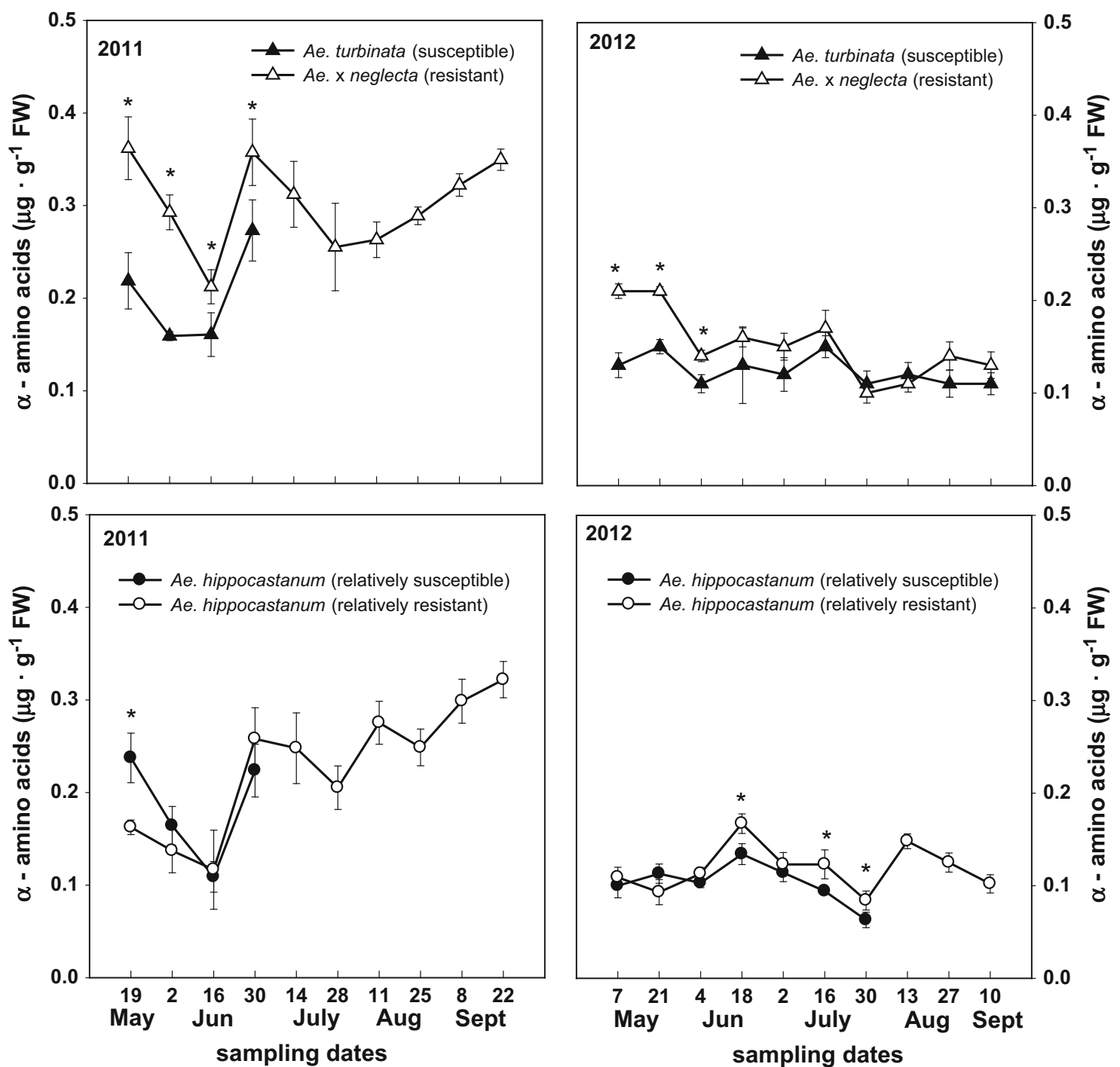

Fig. 7 Level of $\alpha$-amino acids in leaf blades of Japanese horsechestnut (Aesculus turbinata), painted buckeye (Aesculus $\times$ neglecta) and two trees of white horse-chestnut (Aesculus hippocastanum) in

effective defense system which includes antioxidant enzymes and detoxifying enzymes, existing in the larvae midgut, responsible for detoxification of allelochemicals produced by host plants (Żaak et al. 2012). The highest activity of these enzymes was found in the midgut of the second larval generation which correlated with increased toxicity of food caused by the accumulation of secondary metabolites in leaves (Żaak et al. 2012). Our research also revealed that during both growing seasons the concentration of phenolics in leaf blades of susceptible Ae. turbinata was higher than in resistant Ae. $\times$ neglecta. These results do not show that phenolic compounds may be one of the factors responsible for resistance of the examined Ae. $\times$ neglecta individual to $C$. ohridella. Likewise, the results obtained by D'Costa et al. (2014) seem to contradict the role of leaf phenolics in resistance to the pest, because they

2011 and 2012. Data are the means of five replications \pm standard deviation marked as vertical bars. Significant differences between genotypes at the sampling dates are marked as asterisk

showed that leaves of species susceptible (Ae. hippocastanum, Ae. turbinata) to $C$. ohridella were characterized by a higher level of phenolic compounds than leaves of resistant species (Ae. chinensis, Ae. indica) but also had a similar level of these compounds compared to the resistant Ae. flava. The results of other research revealed that red horse-chestnut resistant to $C$. ohridella was characterized by higher content of phenolic compounds, especially (-)epicatechin and procyanidins, as well as a much higher level of saponins, compared to susceptible white horsechestnut (Kukula-Mlynarczyk et al. 2006; Oszmiański et al. 2014). It may suggest that resistance to the pest depends on the qualitative rather than the quantitative profile of phenolic compounds.

Flavonols are compounds that have antinutritive activity and inhibit insect development (Adeyemi et al. 2010; 

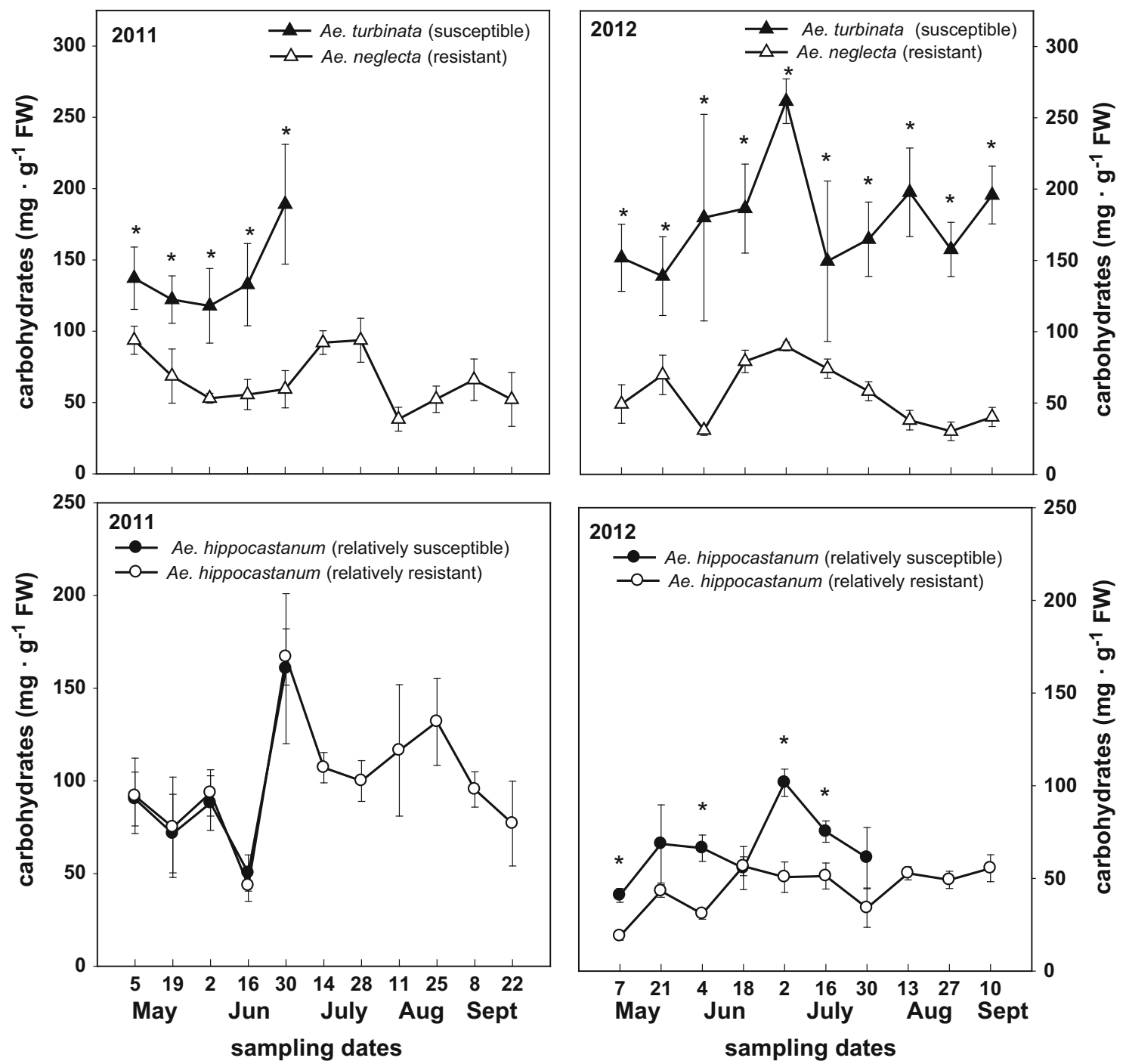

Fig. 8 Level of carbohydrates in leaf blades of Japanese horsechestnut (Aesculus turbinata), painted buckeye (Aesculus $\times$ neglecta) and two trees of white horse-chestnut (Aesculus hippocastanum) in

2011 and 2012. Data are the means of five replications \pm standard deviation marked as vertical bars. Significant differences between genotypes at the sampling dates are marked as asterisk

Martemyanov et al. 2012). A significant increase in the level of flavonols was observed in leaves of the Ae. turbinata tree in July 2012. After this date the damage of leaf blades did not increase. One can assume that the increase of flavonols could be caused by $C$. ohridella larval mining and resulted in the reduction of oviposition by conspecific females from the next pest generation. Therefore, the inhibition of further damage may be caused by induced chemical defense in which flavonols play an important role (War et al. 2012).

An important factor which stimulates larvae to feed is the abundance of nutrients in leaves (Bede et al. 2007). Insects more willingly select leaves that are rich in amino acids and carbohydrates (Glendinning et al. 2007). The level of amino acids in the leaves may be an important factor affecting the size of the phytophagous population.

Insects that feed on tissues rich in amino acids grow faster, are larger and more fertile, and their progeny have a greater chance of survival in comparison to insects which feed on food containing a low level of these compounds (Cahenzli and Erhardt 2013; Marchioro and Foerster 2013). Our results do not confirm that the level of amino acids is a factor which affects the feeding of the horse-chestnut leaf miner. In both years throughout May and June the pestsusceptible Ae. turbinata had a lower amino acid content in leaf blades than the resistant Ae. $\times$ neglecta, whereas in both specimens of Ae. hippocastanum the content of amino acids was at a similar level throughout both growing seasons. Similarly, in other studies amino acid level in leaves of Aesculus species was not a trait which favored oviposition preference of $C$. ohridella and larval feeding (D'Costa et al. 2014). In the midgut of $C$. ohridella there 
are many enzymes catalyzing carbohydrate degradation, which indicates that these compounds are important nutrients for this pest (Stygar et al. 2010). The results of our study confirm the important role of carbohydrates in the stimulation of feeding of the horse-chestnut leaf miner. The pest-susceptible Ae. turbinata tree was found to have, in both growing seasons, a significantly higher level of leaf carbohydrates than the resistant Ae. $\times$ neglecta, while the relatively susceptible Ae. hippocastanum tree contained a slightly higher level of carbohydrates than the relatively resistant ones, but only in 2012. Slightly different and ambiguous results were obtained by D'Costa et al. (2014), who found that Ae. hippocastanum and Ae. turbinata susceptible to $C$. ohridella had similar carbohydrate contents compared to the resistant Ae. chinensis and Ae. indica species, and all these species had lower carbohydrate levels than Ae. flava, resistant to the pest.

In conclusion, the obtained results revealed that traits which may influence oviposition preference and favor the feeding of $C$. ohridella include anthocyanin and carbohydrate levels. The higher leaf carbohydrate content in the susceptible Ae. turbinata tree compared to resistant Ae. $\times$ neglecta suggests that the leaves of the former tree are more valuable food resources for larvae of this pest. Moreover, it may be speculated that the higher anthocyanin level in leaves of the Ae. turbinata specimen affects the leaf color, which may be an attractive visual stimulus for females of $C$. ohridella. However, the differences in the level of these compounds between the two Ae. hippocastanum trees, although statistically significant, are slight and do not explain their different susceptibility. The current results demonstrate that the examined leaf traits do not constitute a complete description of relationships between C. ohridella and examined trees of the genus Aesculus. The chemical composition of horse-chestnut leaves is probably more complex, and many other biochemical and physiological traits are responsible for the multifaceted interaction between this pest and different genotypes of Aesculus sp. The important results of Irzykowska et al. (2013) showed significant inter-species genetic variation within an Ae. hippocastanum population grown in urban green spaces, and 17 molecular markers strongly associated with their susceptibility to $C$. ohridella were found. Broader and more extensive investigations are needed in order to determine the traits that make some Aesculus trees more attractive and why they are willingly colonized by this pest while others are not colonized.

Author contribution statement MP-experimental design, sample collection and chemical analysis in 2011 and 2012, preparation of the manuscript; HB-data analysis, discussion of results and preparation of the manuscript; JW-chemical analysis in 2012; KM and $\mathrm{MG}$-statistical analysis and interpretation of results.

Open Access This article is distributed under the terms of the Creative Commons Attribution 4.0 International License (http://crea tivecommons.org/licenses/by/4.0/), which permits unrestricted use, distribution, and reproduction in any medium, provided you give appropriate credit to the original author(s) and the source, provide a link to the Creative Commons license, and indicate if changes were made.

\section{References}

Adeyemi MM, Adebote DA, Amupitan JO, Oyewale AO, Agbaji AS (2010) Antifeedant activity of quercetin isolated from the stem bark of Bobgunnia madagascariensis (Desv.) J.H.Kirkbr \& Wiersema. (Caesalpiniaceae). Aust J Basic Appl Sci 4:3342-3346

Archetti M, Brown SP (2004) The coevolution theory of autumn colours. Proc R Soc Lond Ser B Biol Sci 271:1219-1223

Baily JL (1962) Techniques in protein chemistry. Elsevier, Amsterdam, pp 73-80

Bede JC, McNeil JN, Tobe SS (2007) The role of neuropeptides in caterpillar nutritional ecology. Peptides 28:185-196

Bernards M, Båstrup-Spohr L (2008) Phenylpropanoid metabolism induced by wounding and insect herbivory. In: Schaller A (ed) Induced resistance to herbivory. Springer, New York, pp 189-211

Bouzouina M, Berkani A, Lotmani B, Amari NO, Ameur S (2012) Effects of Citrus sinensis crude phenol extract on the larval development of Phyllocnistis citrella Staint. (Lepidoptera: Gracillariidae). Bulg J Agric Sci 18:334-341

Cahenzli F, Erhardt A (2013) Nectar amino acids enhance reproduction in male butterflies. Oecologia 171:197-205

Coelho AL (2004) Correlated responses to divergent artificial selection in vegetative anthocyanin expression. In: Resistance of Brassica rapa L. (Brassicaceae) to multiple enemies. Ph.D. thesis, Stony Brook University, pp 136-186

D’Costa L, Koricheva J, Straw N, Simmonds MJS (2013) Oviposition patterns and larval damage by the invasive horse-chestnut leaf miner Cameraria ohridella on different species of Aesculus. Ecol Entomol 38:456-462

D'Costa L, Simmonds MJS, Straw N, Castagneyrol B, Koricheva J (2014) Leaf traits influencing oviposition preference and larval performance of Cameraria ohridella on native and novel host plants. Entomol Exp Appl 152:157-164

Day A (1993) Relating UV-B radiation screening effectiveness of foliage to absorbing-compound concentration and anatomical characteristics in a diverse group of plants. Oecologia 95:542-550

Dimić N, Mihajlović L, Vukća M, Perić P, Krnjajić S, Cvetković M (2000) Development of Cameraria ohridella Deschka \& Dimić, 1986 (Lepidoptera, Gracillariidae). Entomofauna Z Entomol 21:5-12

Ferracini C, Curir P, Dolci M, Lanzotti V, Alma A (2010) Aesculus pavia foliar saponins: defensive role against the leafminer Cameraria ohridella. Pest Man Sci 66:767-772

Girardoz S, Quicke DLJ, Kenis M (2007) Factors favouring the development and maintenance of outbreaks in an invasive leaf miner Cameraria ohridella (Lepidoptera: Gracillariidae): a life table study. Agric For Entom 9:141-158 
Glendinning JI, Jerud A, Reinherz AT (2007) The hungry caterpillar: an analysis of how carbohydrates stimulate feeding in Manduca sexta. J Exp Biol 210:3054-3306

Hiscox JC, Israelstam GF (1979) A method for the extraction of chlorophyll from tissue without maceration. Can $\mathrm{J}$ Bot 57:1332-1334

Irzykowska L, Werner M, Bocianowski J, Karolewski Z, FrużyńskaJóźwiak D (2013) Genetic variation of horse chestnut and red horse chestnut and susceptibility on Erysiphe flexuosa and Cameraria ohridella. Biologia 68:851-860

Jaworski T, Hiszczański J (2013) The effect of temperature and humidity changes on insects development and their impact on forest ecosystems in the context of expected climate change. For Res Paper 74:345-355

Johne AB, Weissbecker B, Schütz S (2006a) a) Volatile emissions from Aesculus hippocastanum induced by mining of larval stages of Cameraria ohridella influence oviposition by conspecific females. J Chem Ecol 32:2303-2319

Johne AB, Weissbecker B, Schütz S (2006b) b) Reduzierung der Eiablage von C. ohridella (Deschka \& Dimic) durch repellents. Nachr Deut Pflanz 58:260-261

Johne AB, Weissbecker B, Schütz S (2006c) c) Microorganisms on Aesculus hippocastanum-olfactory perspective of Cameraria ohridella (Deschka \& Dimic). Mitt Dtsch Ges Allg Angew Ent 15:147-151

Johne AB, Weissbecker B, Schütz S (2008) Approaching risk assessment of complex disease development in horse chestnut trees: a chemical ecologist's perspective. J Appl Entomol 132:349-359

Jonas JL, Joern A (2013) Dietary selection and nutritional regulation in a common mixed-feeding insect herbivore. Entomol Exp Appl 148:20-26

Karageorgou P, Manetas Y (2006) The importance of being red when young: anthocyanins and the protection of young leaves of Quercus coccifera from insect herbivory and excess light. Tree Physiol 26:613-621

Karageorgou P, Buschmann C, Manetas Y (2008) Red leaf color as a warning signal against insect herbivory: honest or mimetic? Flora 203:648-652

Kenis M, Girardoz S, Avtzis N, Kamata N (2003) Finding the area of origin of the horse-chestnut leaf miner: a challenge. In: International symposium of IUFRO Kanazawa. "Forest insect population dynamics and host influences", pp 63-66

Kočíková L, Miklisová D, Čanády A, Panigaj L (2012) Is colour an important factor influencing the behaviour of butterflies (Lepidoptera: Hesperioidea, Papilionoidea)? Europ J Entomol 109:403-410

Kropczyńska-Linkiewicz D, Tomczyk A, Polewczyńska E (2008) Susceptibility of white horse chestnut grafted on white horse chestnut (Aesculus hippocastanum L.) and red-flowering horse chestnut (Aesculus $\times$ carnea Hayne) to horse chestnut leaf-miner (Cameraria ohridella Deschka and Dimić). Progress Plant Prot 48:1351-1354

Kukuła-Młynarczyk A, Hurej M (2007) Incidence, harmfulness and some elements of horse chestnut leafminer (Cameraria ohridella Deschka \& Dimić) control on white horse chestnut (Aesculus hippocastanum L.). J Plant Prot Res 47:53-64

Kukuła-Młynarczyk A, Hurej M, Jackowski J (2006) Development of horse chestnut leafminer (Cameraria ohridella Deschka \& Dimić) on red horse chestnut. J Plant Prot Res 46:41-47

Lev-Yadun S, Gould KS (2009) Role of anthocyanins in plant defence. In: Gould K, Davies K, Winefield Ch (eds) Anthocyanins, biosynthesis, functions, and applications. Springer, New York, pp 21-48

Luo X, Huang Q (2011) Relationships between leaf and stem soluble sugar content and tuberous root starch accumulation in cassava. J Agric Sci 3:64-72
Marchioro CA, Foerster LA (2013) Effects of adult-derived carbohydrates and amino acids on the reproduction of Plutella xylostella. Physiol Entomol 38:13-19

Martemyanov VV, Dubovskiy IM, Belousova IA, Pavlushin SV, Domrachev DV, Rantala MJ, Salminen J-P, Bakhvalov SA, Glupov VV (2012) Rapid induced resistance of silver birch affects both innate immunity and performance of gypsy moths: the role of plant chemical defenses. Arthropod Plant Interact 6:507-518

Maskato Y, Talal S, Keasar T, Gefen E (2014) Red foliage colour reliably indicates low host quality and increased metabolic load for development of an herbivorous. Arthropod Plant Interact $8: 285-292$

Mithöfer A, Boland W (2012) Plant defense against herbivores: chemical aspects. Annu Rev Plant Biol 63:431-450

Ossipov V, Haukioja E, Ossipopva S, HanhimäkiS Pihlaja K (2001) Phenolic and phenolic-related factors as determinants of suitability of mountainbirch leaves to an herbivorus insect. Biochem Syst Ecol 29:223-240

Oszmiański J, Kalisz S, Wojdyło A (2014) The content of phenolic compounds in leaf tissue of white (Aesculus hippocastanum L.) and red horse chestnut (Aesculus carnea $\mathrm{H}$.) colonized by the horse chestnut leaf miner (Cameraria ohridella Deschka \& Dimić). Molecules 19:14625-14636

Pál M, Bálint J, Balog A (2014) Using the technique of vegetal endometry against the horse chesnut's leaf miner (Lepidoptera: Cameraria ohridella Deschka \& Dimić) Scientific Papers. Series B, Horticulture LVIII, pp 353-358

Prada D, Velloza TM, Toorop PE, Pridchar HW (2011) Genetic population structure in horse chestnut (Aesculus hippocastanum L.): effect of human-mediated expansion in Europe. Plant Spec Biol 26:43-50

Reinhardt F, Herle M, Bastiansen F, Streit B (2003) Economic impact of the spread of alien species in Germany. In: Environmental Research of the Federal Ministry of the Environment, Nature Conservation and Nuclear Safety: research report 20186211 UBA-FB 000441e

Sambangi P, Usha Rani P (2013) Induction of phenolic acids and metals in Arachis hypogaea L. plants due to feeding of three lepidopteran pests. Arthropod Plant Interact 7:517-525

Schaefer HM, Rolshausen G (2006) Plants on red alert: do insects pay attention? BioEssays 28:65-71

Stefova M, Kulevanova S, Stafilov T (2001) Assay of flavonols and quantification of quercetin in medicinal plants by HPLC with UV-diode array detection. J Liq Chrom Relat Technol 24:2283-2292

Straw NA, Tilbury C (2006) Host plants of the horse-chestnut leafminer (Cameraria ohridella), and the rapid spread of the moth in the UK 2002-2005. Arboricult J 29:83-99

Stygar D, Doleżych B, Nakonieczny M, Migula P, Michalczyk K, Żaak M (2010) Digestive enzymes activity in larvae of Cameraria ohridella (Lepidoptera: Gracillariidae). CR Biol 333:725-735

Svatos A, Kalinová B, Hrdý I (2009) Cameraria ohridella: 10 years of sex pheromone and kairomone research. J Appl Entomol 133:319-327

Swain J, Hillis WE (1959) The phenolic constituents of Prumus domestical. The quantitative analysis of phenolic constituents. J Sci Food Agric 10:63-68

Tilbury C, Straw N, Evans AH (2004) Recent establishment of horse chestnut leaf-miner Cameraria ohridella, in the UK. In: Proceedings of the first international Cameraria symposium, 2004, Prague, 24-27 March 2004, p 43

Tomiczek C, Krehan H (1998) The horsechestnut leafmining moth (Cameraria ohridella): a new pest in central Europe. J Arboricult 24:144-148 
Valade R, Kenis M, Hernandez-Lopez A, Augustin S, Mari Mena N, Magnoux E, Rougerie R, Lakatos F, Roques A, LopezVaamonde C (2009) Mitochondrial and microsatellite DNA markers reveal a Balkan origin for the highly invasive horsechestnut leaf miner Cameraria ohridella (Lepidoptera, Gracillariidae). Mol Ecol 18:3458-3470

Wang H, Arakawa O, Motomura Y (2000) Influence of maturity and bagging on relationship between anthocyanin accumulation and phenylalanine ammonia-lyase (PAL) activity in 'Jonathan' apples. Postharvest Biol Technol 19:123-128

War AR, Paulraj MG, Ahmad T, Buhroo AA, Hussain B, Ignacimuthu S, Chand H, Sharma HC (2012) Mechanisms of plant defense against insect herbivores. Plant Signal Behav 7:1306-1320
Wellburn AR (1994) The spectral determination of chlorophylls $a$ and $b$, as well as total carotenoids, using various solvents with spectrophotometers of different resolution. J Plant Physiol 144:307-313

Żaak M, Migula P, Stygar D, Doleżych B, Michalczyk K (2012) Within and between seasonal changes of detoxifying capabilities of Cameraria ohridella (Lepidoptera: Gracillariidae) larvae. C R Biol 335:645-656

Zhang Y-F, Huang L-Q, Ge F, Wang C-Z (2011) Tarsal taste neurons of Helicoverpa assulta (Guenée) respond to sugars and amino acids, suggesting a role in feeding and oviposition. J Insect Physiol 57:1332-1340 